\title{
Spatial and spatio-temporal analysis of malaria in the state of Acre, western Amazon, Brazil
}

\author{
Leonardo Augusto Kohara Melchior, ${ }^{1,2}$ Francisco Chiaravalloti Neto' \\ ${ }^{1}$ Federal University of Acre, Brazil; ${ }^{2}$ Faculty of Public Health, University of São Paulo, São \\ Paulo, Brazil
}

\begin{abstract}
Since 2005, the State of Acre, western Amazon, Brazil, has reported the highest annual parasite incidence (API) of malaria among the Brazilian states. This study examines malaria incidence in Acre using spatial and spatio-temporal analysis based on an ecological time series study analyzing malaria cases and deaths for the time period 19922014 and using secondary data. API indexes were calculated by age, sex, parasite species, ratio of Plasmodium vivax to $P$. falciparum malaria, malaria mortality rate and case fatality rate. SaTScan was used to detect spatial and spatio-temporal clusters of malaria cases
\end{abstract}

Correspondence: Leonardo A.K. Melchior, Universidade Federal do Acre, Campus Universitário, BR 364, Km 04, CEP 69.920-900, Rio Branco, Acre, Brazil.

Tel: +55.68 .3901 .2524 - Fax: +55.68 .9229 .3570 .

E-mail: Imelchior@gmail.com

Key words: Malaria; Geographical information system; Clusters; Amazon; Brazil.

Acknowledgments: the authors would like to thank Eliana Costa and Dorian Jinkins at SESACRE Division of Health Surveillance, Maria Lucia Ferraz at FSP/USP Library and FSP/USP Faculty members Fredi Alexander Díaz Quijano and Cassia Maria Buchalla for their inputs. Lastly, the authors would like to acknowledge the support of Federal University of Acre, Rio Branco, Brazil.

Contributions: the authors contributed equally.

Conflict of interest: the authors declare no potential conflict of interest.

Funding: this study project was funded by Coordination for the Improvement of Higher Education Personnel, Brasília, Brazil (CAPES/MEC/Brazil).

Received for publication: 17 December 2015.

Revision received: 17 May 2016.

Accepted for publication: 17 May 2016.

(C) Copyright L.A. Kohara Melchior and F. Chiaravalloti Neto, 2016

Licensee PAGEPress, Italy

Geospatial Health 2016; 11:443

doi:10.4081/gh.2016.443

This article is distributed under the terms of the Creative Commons Attribution Noncommercial License (CC BY-NC 4.0) which permits any noncommercial use, distribution, and reproduction in any medium, provided the original author(s) and source are credited. and data were represented in the form of choropleth maps. A high-risk cluster of malaria was detected in Vale do Juruá and three low-risk clusters in Vale do Acre for both parasite species. Those younger than 19 years of age and females showed a high incidence of malaria in Vale do Juruá, but working-age males were the most affected in Vale do Acre. The malaria mortality rate showed a decreasing trend across the state, while the case fatality rate increased only in the micro-region of Rio Branco during the study period. We conclude that malaria is a focal disease in Acre showing different spatial and spatio-temporal patterns of cases and deaths that vary by age, sex, and parasite species. Malaria incidence is thought to be influenced by factors related to regional characteristics; therefore, appropriate disease and vector control strategies must be implemented at each locality.

\section{Introduction}

Malaria has been a scourge of humanity since antiquity and it remains so today presenting a major challenge to global public health (CDC, 2012; WHO, 2015). Malaria is an acute febrile infectious and parasitic disease caused by protozoa of the genus Plasmodium transmitted by Anopheles mosquitoes (Brasil, 2003). It accounts for high morbidity and mortality worldwide and the most affected regions are Africa, South America and Asia (Levinson, 2014).

In the Americas, Brazil accounts for over 50\% of malaria cases and 98\% of them occur across six states in the Amazon: Acre, Amapá, Amazonas, Pará, Rondônia, and Roraima. From 2000 to 2011, there was a reduction in the number of malaria cases in all states in this macro-region except for the state of Acre, which reported a $4.8 \%$ increase (Brasil, 2013).

Since 2005, the State of Acre has reported the highest annual incidence of malaria among the Brazilian states. The 2006 malaria epidemic exacted an extraordinary toll: 93,864 cases, most of them reported from the micro-region of Cruzeiro do Sul (DATASUS, 2015).

It is known that malaria cases are not evenly distributed in space (Confalonieri, 2005; Atanaka-Santos et al., 2006; Valle and Lima, 2014). As the malaria risk is also unevenly distributed in the endemic areas (Confalonieri, 2005), geographic information systems (GIS) are useful for spatial analysis because they allow surveying and understanding the epidemiological behaviour of emerging and re-emerging infectious diseases (Ceccato et al., 2005; Machault et al., 2011; Delgado-Petrocelli et al., 2011; Franke et al., 2015 ).

This study aimed to assess malaria incidence in the state of Acre, Brazil using spatial and spatial-temporal analysis based on secondary data obtained from national malaria databases. 


\section{Materials and Methods}

\section{Study area}

The study area is the State of Acre, which is located in the southwestern Brazilian Amazon with an area of $164,123,739 \mathrm{~km}^{2}$. It borders the states of Amazonas (N) and Rondônia (E), has international borders with Bolivia (S) and Peru (W) and is subdivided into two mesoregions (Vale do Acre and Vale do Juruá) and five micro-regions (Rio Branco, Brasileia, Sena Madureira, Cruzeiro do Sul, and Tarauacá) altogether comprising 22 municipalities (Figure 1). The 2010 Population Census reported 733,559 people living in Acre (IBGE, 2015).

\section{Malaria data}

We obtained information on malaria cases for 2000 to 2014 from the State of Acre Health Department (SESACRE), Malaria Information System (SISMAL) up to the year 2003 and from the Epidemiological Surveillance Information System (SIVEP/Malaria) - an upgraded version of SISMAL - for the year 2003 and onwards. National and Amazon regional data for 2003 to 2012 were obtained from the National Health System Department of Information Technology (DATASUS). All these databases are managed by the Brazilian Ministry of Health Disease

\section{Surveillance department}

Data on malaria mortality for the period 1992 to 2014 was obtained by place of residence from the DATASUS Mortality Information System (SIM) and demographic data and population estimates by age and sex from the Brazilian Institute of Geography and Statistics (IBGE).

\section{Descriptive data analysis}

We calculated the annual parasite incidence (API) (confirmed cases during 1 year for the population under surveillance $\times 1000)$. To improve the accuracy of identifying the probable location where malaria infection was acquired, we included only autochthonous cases in the calculation of this index. This information was available for the years 2003 to 2014. The units of analysis were meso-regions, micro-regions and municipalities. Malaria incidence was estimated by age (confirmed cases by age group during 1 year per the population under surveillance in that age group $\times 1000$ ) and sex (confirmed cases during 1 year per the population under surveillance $\times 1000)$ in all meso-regions and micro-regions from 2003 to 2012 . We also calculated API by parasite species, Plasmodium vivax (PvAPI), P. falciparum (PfAPI) and both parasite species, in all meso-regions and micro-regions from 2000 to 2014. Since no information was available on the origin of malarial infection, the analyses were carried out regardless of whether cases were autochthonous or not. We also calculated the ratio of $P$. vivax to $P$. falciparum malaria (V/F) (confirmed cases for $P$. vivax malaria divided by confirmed cases for $P$. falciparum malaria). In addition, we estimated the malaria mortality rate (MMR) (total malaria deaths in the period in the population under surveillance $\times 100,000)$ and case fatality rate (CFR) (total annual, reported malaria deaths divided by total number of positive slides, multiplied by 1000) in all meso-regions, micro-regions, and municipalities from 1992 to 2012.

\section{Spatial cluster analysis}

We used SaTScan ${ }^{\mathrm{TM}}$, version 9.4.1 (Kulldorff, 2015) to examine spatial and spatio-temporal clustering of cases and deaths from $P$. vivax and $P$. falciparum malaria in the municipalities. This statistical approach allows identifying whether cases were randomly distributed or clustered in space and space-time (Mosha et al., 2014). SaTScan ${ }^{\mathrm{TM}}$ made it possible to test if we should accept the alternative hypothesis $\left(\mathrm{H}_{\mathrm{A}}=\right.$ individuals of a particular area are more likely to suffer from the disease) or the null hypothesis $\left(\mathrm{H}_{0}=\right.$ all the individuals of a given population are equally likely to suffer from the disease). The established statistical significance level was 5\%.

Three data banks were connected to the programme for the analysis: one with the latitudes and longitudes of the centroids of each municipality, another with the populations of the municipalities by year, and a third with the number of cases per municipality and by year. For the identification of the spatial clusters, Poisson's discrete model was constructed with the following configurations: non-occurrence of geographical cluster overlapping, clusters of maximum size equal to $50 \%$ of the exposed population, circular sets and 999 repetitions. This approach only considers the space in which the cases occurred (Kulldorff, 2015). To aggregate the variable time of the model, the space-time mode of the SaTScan ${ }^{\mathrm{TM}}$ programme was used, thus identifying potential space-time clusters. The same configurations of the maximum size of the clusters were equal to $50 \%$ of the period of the study and the measurement of time was standardized in years (Kulldorff $e t$ $a l ., 2005)$. Both the space and space-teime scanning techniques were

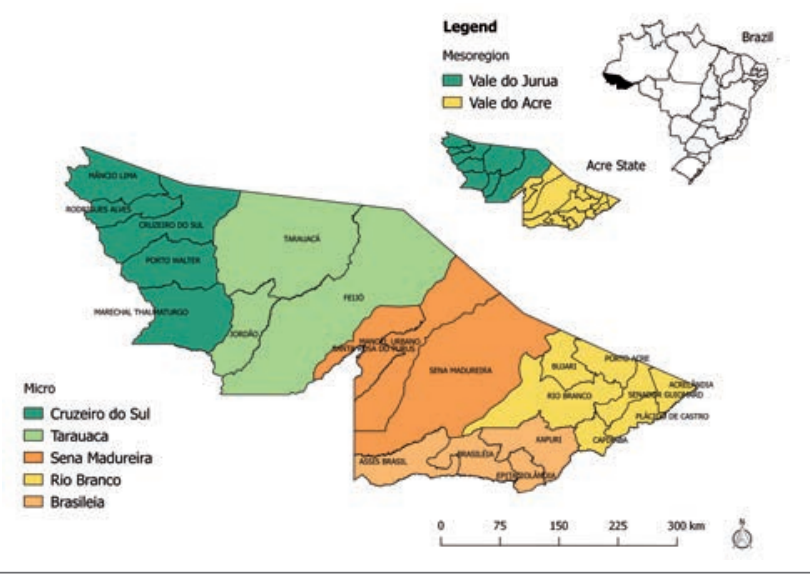

Figure 1. Geographical location of the state of Acre and its territorial divisions, Brazil.

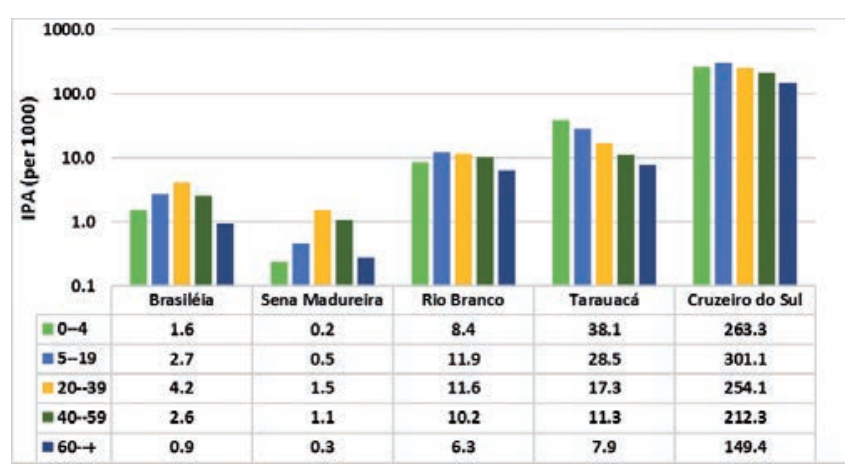

Figure 2. Annual parasite incidence of malaria on a logarithmic scale by age and micro-region, State of Acre, Brazil (2003-2012). 
adjusted according to the population of the municipalities and set to detect clusters of high and low risk for $P$. vivax and $P$. falciparum malaria. The test of the significance of the clusters identified was based on the comparison of the null distribution obtained by Monte Carlo simulation and the statistical ratio test of verisimilitude (Abrams and Kleinman, 2007). The programme presented the relative risk of each cluster, so that different areas might be compared with each other.

Statistically significant clusters of high and low risk were presented in thematic maps developed by means of the free software QGIS 2.8 Wien LTR (https://communityhealthmaps.nlm.nih.gov/2015/03/02/qgis2-8-1-released/) taking as basis the digital network Município 2013 of the IBGE. Data were entered into Microsoft Office Excel (2013) spreadsheets and the indicators calculated.

\section{Ethical considerations}

This research project was reviewed and approved by the Federal University of Acre and University of São Paulo, School of Public Health research ethics committees (institutional review board protocol number 41731515.4.0000.5010). SESACRE approved the use of data from the malaria reporting systems.

\section{Results}

\section{Descriptive data analysis}

Our data analysis showed that API for Acre, during the period from 2003 to 2014, was 34.7 cases per 1000 inhabitants and that malaria occurred predominantly in Vale do Juruá, specifically in the microregion of Cruzeiro do Sul. All other locations had much lower API indexes (Table 1). In this period, the API indexes in Vale do Juruá were much higher than those seen in Vale do Acre. However, there was a decline in the indexes in Vale do Acre from 2008 onwards that eventually became as low as the nationwide average rate. The average difference of API between these two meso-regions increased from 7 to 212 times. API in Vale do Juruá increased because of the high number of malaria cases in the municipalities of Cruzeiro do Sul, Mâncio Lima and Rodrigues Alves, totalling $98.6 \%$ of cases.

From 2003 to 2012, the most affected population groups in Cruzeiro

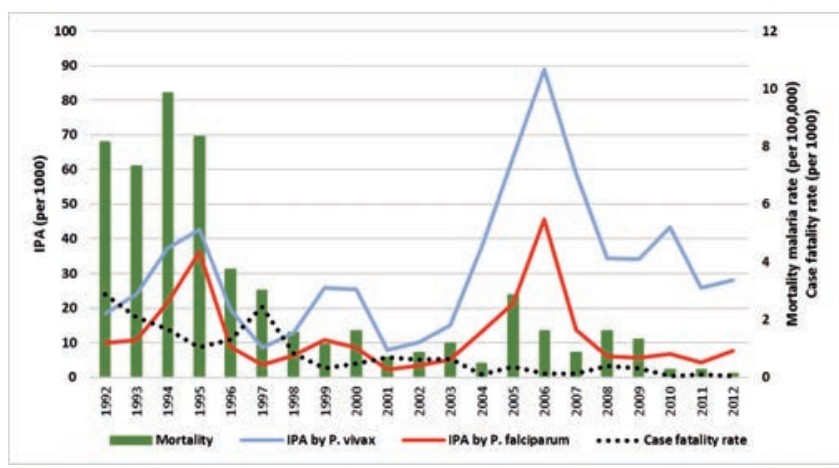

Figure 3. Historical series of annual parasite incidence of malaria mortality rate and case fatality rate in the State of Acre, Brazil (1992-2012). do Sul were those aged 5-19 years, followed (in order) by those aged 04 years, $20-39$ years, $40-59$ years and 60 and over (Figure 2 ). The malaria cases in the micro-region of Tarauacá had a behaviour similar to that of Cruzeiro do Sul, i.e. children aged 0-4 years were the most affected, though at rates 6 to 18 times lower. In Vale do Acre, people aged 5-19 years, 20-39 years, and 40-50 years were the most affected. In the micro-region of Sena Madureira and Brasileia, the lowest incidence rates were observed among children aged $0-4$ years and in the elders. In this period, male cases were more prevalent in all microregions. However, the ratio of male to female cases was 2.0 in Vale do Acre and 1.2 in Vale do Juruá, suggesting a more balanced sex distribution in the latter. The sex ratios of API were (in ascending order): 1.2 in Cruzeiro do Sul and 1.3 in Tarauacá in Vale do Juruá; 2.0 in Rio Branco; 2.7 in Brasileia; and 3.2 in Sena Madureira in Vale do Acre. From 2000 to 2014, PvAPI was higher than PfAPI in all microregions. The ratio of V/F malaria was 3.1 and 3.2 in Vale do Acre and Vale do Juruá, respectively; 4.8 in the micro-region of Tarauacá; 3.1 in Cruzeiro do Sul and Rio Branco; 2.2 in Brasileia; and 1.9 in Sena Madureira. There was a downward trend in MMR across Acre from 1992 to 2012, in parallel with the worldwide trend (Figure 3). From 1990 to 2000, the average MMRs in Vale do Acre and Vale do Juruá were 3.4 and 10.3 deaths per 100,000 population, respectively. From 2001 to 2012, these rates fell to 0.6 and 2.1 deaths per 100,000 population, respectively. Cruzeiro do Sul showed the highest MMR (8 deaths per 100,000) in the period 2001 a 2012 compared to the neighbouring Tarauacá, which had the lowest rates, almost close to zero ( 0.4 deaths per $100,000)$. MMR ranged from 1-2 deaths per 100,000 in the microregions of Vale do Acre.
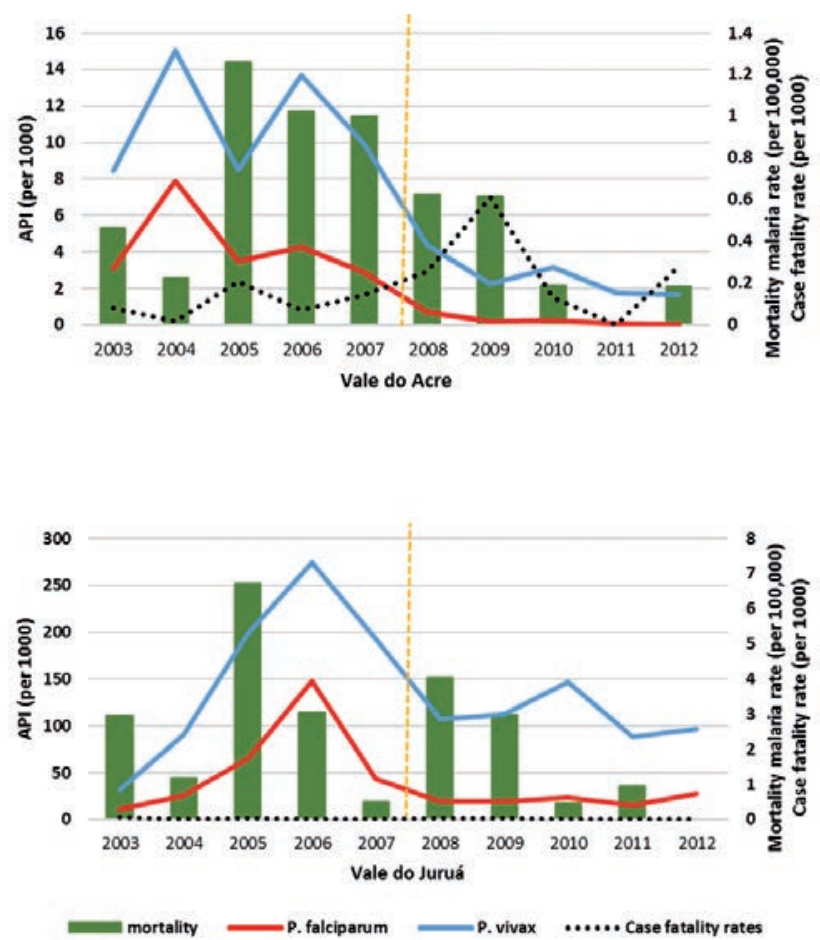

Figure 4. Comparistion of historical series of malaria mortality rates, case fatality rates and annual parasite incidence of malaria by parasite species between Vale do Juruá and Vale do Acre, State of Acre, Brazil (2003-2012). 
The number of malaria deaths was 11 per 100,000 in Cruzeiro do Sul; 5 per 100,000 in Mâncio Lima; and 3 per 100,000 in Rodrigues Alves, Capixaba, Senador Guiomard and Plácido de Castro. The state capital Rio Branco accounted for $32 \%$ of malaria deaths in Acre, with a rate of 2 deaths per 100,000 . All other municipalities had lower rates. When we divided the study period of 2003-2012 into two five-year periods (20032007 and 2008-2012), CFR in Cruzeiro do Sul had an effect on the rate of Vale do Juruá keeping it steady between the two five-year periods (CFR=0.014). Because of a high number of deaths in Rio Branco, CFR in Vale do Acre increased from 0.08 to 0.25 (Figure 4). All other microregions in Vale do Acre showed a negative CFR trend.

\section{Cluster analysis}

The spatio-temporal analysis from 2003 to 2013 revealed clustering of malaria deaths from 2003 to 2009 in 4 municipalities in the microregion of Cruzeiro do Sul: Cruzeiro do Sul, Mâncio Lima, Rodrigues Alves, and Porto Walter (Figure 5; Table 2). The purely spatial cluster analysis of malaria deaths showed a high-risk area in Vale do Juruá and a low-risk area in Vale do Acre (Figure 5). The purely spatial cluster analysis indicated a non-random distribution of malaria in the study area. Only 3 municipalities had high risk for both $P$. vivax and $P$. falciparum malaria transmission. The analysis showed 3 low-risk clusters during the study period (Figure 6). Acrelândia, Plácido de Castro and Capixaba were the only ones not included in the low-risk cluster 3 (L3) for P. vivax malaria transmission. To verify the statistical signifi-

Table 1. Annual parasite incidence of autochthonous cases in the meso-regions and micro-regions of the State of Acre, Brazil, 20032014.

\begin{tabular}{|c|c|c|c|}
\hline & & API (per 1000) & Number of cases \\
\hline Meso-regions & $\begin{array}{l}\text { Vale do Juruá } \\
\text { Vale do Acre }\end{array}$ & $\begin{array}{c}149.1 \\
4.5\end{array}$ & $\begin{array}{c}357,082 \\
26,123\end{array}$ \\
\hline Micro-regions & $\begin{array}{c}\text { Cruzeiro do Sul* } \\
\text { Tarauacá } \\
\text { Rio Branco } \\
\text { Brasileia } \\
\text { Sena Madureira }\end{array}$ & $\begin{array}{c}222.9 \\
19.3 \\
5.4 \\
1.4 \\
0.3\end{array}$ & $\begin{array}{c}340,366 \\
16,716 \\
25,057 \\
914 \\
152\end{array}$ \\
\hline Municipalities of Cruzeiro do Sul* & $\begin{array}{c}\text { Mâncio Lima } \\
\text { Rodrigues Alves } \\
\text { Cruzeiro do Sul } \\
\text { Porto Walter } \\
\text { Marechal Thaumaturgo }\end{array}$ & $\begin{array}{c}388.6 \\
319.4 \\
235.3 \\
36.2 \\
7.8\end{array}$ & $\begin{array}{c}68,010 \\
50,747 \\
216,514 \\
3783 \\
1312 \\
\end{array}$ \\
\hline
\end{tabular}

API, annual parasite incidence. *Epidemic micro-region.

Table 2. The clusters of malaria deaths and cases by Plasmodium vivax/falciparum detected using purely spatial and space-time analysis.

\begin{tabular}{|c|c|c|c|c|c|c|c|c|}
\hline & & Type & $\begin{array}{l}\text { Coordinates/ } \\
\text { radius } \\
(\mathrm{km})\end{array}$ & $\begin{array}{l}\text { Observed } \\
\text { cases }\end{array}$ & $\begin{array}{l}\text { Expected } \\
\text { cases }\end{array}$ & $\begin{array}{l}\text { Relative } \\
\text { risk }\end{array}$ & $\begin{array}{l}\text { Log } \\
\text { likelihood } \\
\text { ratio }\end{array}$ & $P$ \\
\hline \multirow{9}{*}{$\begin{array}{l}\text { Purely } \\
\text { spatial } \\
\text { analysis }\end{array}$} & $\begin{array}{l}\text { Deaths } \\
\text { (2003-2013) }\end{array}$ & $\begin{array}{l}\mathrm{H} \\
\mathrm{L} 1\end{array}$ & $\begin{array}{c}7.98 \mathrm{~S}, 72.75 \mathrm{~W} / 91.50 \\
10.57 \mathrm{~S}, 68.50 \mathrm{~W} / 58.46\end{array}$ & $\begin{array}{l}41 \\
20\end{array}$ & $\begin{array}{l}11.55 \\
37.84\end{array}$ & $\begin{array}{l}6.53 \\
0.36\end{array}$ & $\begin{array}{l}30.56 \\
8.72\end{array}$ & $\begin{array}{l}0.00 \\
0.00\end{array}$ \\
\hline & Plasmodium vivax & $\mathrm{H}$ & $7.50 \mathrm{~S}, 73.44 \mathrm{~W} / 91.50$ & 280,508 & 50289 & 32.04 & 397310.38 & 0.00 \\
\hline & $(2003-2014)$ & L1 & $10.57 \mathrm{~S}, 68.50 \mathrm{~W} / 58.46$ & 5164 & 163808 & 0.016 & 200123.57 & 0.00 \\
\hline & & L2 & $9.38 \mathrm{~S}, 69.85 \mathrm{~W} / 167.41$ & 1095 & 50208 & 0.019 & 49015.79 & 0.00 \\
\hline & & L3 & $9.63 \mathrm{~S}, 67.7 \mathrm{~W} / 52.10$ & 6783 & 20332 & 0.32 & 6396.23 & 0.00 \\
\hline & Plasmodium falciparum & $\mathrm{H}$ & 7.50S, 73.44W/91.50 & 91185 & 16136 & 35.13 & 131632.89 & 0.00 \\
\hline & $(2003-2014)$ & L1 & $10.57 \mathrm{~S}, 68.50 \mathrm{~W} / 58.46$ & 1673 & 52559 & 0.016 & 64144.27 & 0.00 \\
\hline & & $\mathrm{L} 2$ & $9.38 \mathrm{~S}, 69.85 \mathrm{~W} / 167.41$ & 292 & 16109 & 0.015 & 15968.92 & 0.00 \\
\hline & & L3 & $9.93 \mathrm{~S}, 66.95 \mathrm{~W} / 138.59$ & 6014 & 12111 & 0.47 & 2081.72 & 0.00 \\
\hline \multirow[t]{9}{*}{$\begin{array}{l}\text { Space-time } \\
\text { analysis }\end{array}$} & $\begin{array}{l}\text { Deaths } \\
(2003-2013)\end{array}$ & H (2003-2009) & 7.98S, 72.75W/91.50 & 37 & 5.72 & 11.65 & 46.10 & 0.00 \\
\hline & Plasmodium vivax & H (2005-2010) & 7.50S, 73.44W/91.50 & 183275 & 25124.45 & 15.21 & 257094.9 & 0.00 \\
\hline & (2003-2014) & L1 (2009-2014) & $10.57 \mathrm{~S}, 68.50 \mathrm{~W} / 58.46$ & 778 & 87371.93 & 0.0066 & 96856.65 & 0.00 \\
\hline & & L2 (2009-2014) & $9.38 \mathrm{~S}, 69.85 \mathrm{~W} / 167.41$ & 205 & 26312.01 & 0.0072 & 26206.51 & 0.00 \\
\hline & & L3 (2009-2014) & $9.93 \mathrm{~S}, 66.95 \mathrm{~W} / 138.59$ & 3360 & 19707.43 & 0.16 & 10827.97 & 0.00 \\
\hline & Plasmodium falciparum & H (2004-2007) & $7.50 \mathrm{~S}, 73.44 \mathrm{~W} / 91.50$ & 51811 & 5303.31 & 18.22 & 84582 & 0.00 \\
\hline & $(2003-2014)$ & L1 (2009-2014) & $10.57 \mathrm{~S}, 68.50 \mathrm{~W} / 58.46$ & 51 & 28033.74 & 0.0013 & 32193.36 & 0.00 \\
\hline & & L2 (2009-2014) & $9.38 \mathrm{~S}, 69.85 \mathrm{~W} / 167.41$ & 11 & 8442.35 & 0.0012 & 8714.06 & 0.00 \\
\hline & & L3 (2009-2014) & $9.93 \mathrm{~S}, 66.95 \mathrm{~W} / 138.59$ & 112 & 6323.23 & 0.017 & 5949.91 & 0.00 \\
\hline
\end{tabular}

H, high-risk; L1, low-risk 1; L2, low-risk 2; L3, low-risk 3. 
cance of the distribution of malaria transmission risk in space and time in high- and low-risk clusters from 2003 to 2014 we performed the cluster analysis according to Kulldorff (2015). There were found major similarities in both parasite species malaria, but high-risk clusters of $P$. falciparum malaria occurred from 2004 to 2007 and of $P$. vivax malaria occurred from 2005 to 2010 (Figure 7).

\section{Discussion}

The public health authorities in Acre have paid a great deal of attention to the meso-region of Vale do Juruá because of high APIs in the municipalities of Mâncio Lima, Rodrigues Alves and Cruzeiro do Sul in the micro-region of Cruzeiro do Sul. We detected high-risk clustering of malaria in these municipalities for the study period in all analyses. Other authors have advocated elsewhere that this microregion needs to be a priority area for malaria prevention and control interventions (Valle and Lima, 2014). Several local environmental factors directly affect malaria transmission in these localities, including communities living in the vicinity of forest areas in disorderly housing settlements with poor sanitation; operational difficulties of local surveillance systems; and movements of infected populations either into or out of malarious areas (Costa et al., 2010).

Local economic practices such as wood extraction and establishment of livestock pastures have not only a high environmental impact but have also an effect on the epidemiology of malaria (Natal et al., 1992; Castro and Singer, 2007; da Silva-Nunes et al., 2008). Several authors have underscored that fish farming is another economic activity that can potentially affect vector proliferation and consequently increase malaria transmission (Costa et al., 2010; Olson et al., 2010; Braz et al., 2012; Valle and Lima, 2014). In 2005, State Government agencies excavated the land to build water reservoirs in a number of municipalities in the micro-region of Cruzeiro do Sul. However, many construction sites were later abandoned because of lack of planning and resources. Without proper maintenance and cleaning of the surrounding environment, these unbuilt reservoirs have become breeding sites for Anopheles mosquitoes (Costa et al., 2010). This episode is believed to be closely related to the major epidemic of malaria in the region in 2006. In addition, in that same year, there were approximately 430 ha of fish farming ponds solely in Mâncio Lima (Olson et al., 2010).

Almost all low-risk clusters of malaria identified were located in Vale do Acre, where the state capital Rio Branco is located. It is a more economically developed, anthropic area with several rural properties of beef cattle farming established on land deforested long ago. The spatiotemporal analysis revealed that low-risk clusters occurred from 2009 to 2014, which suggests a decline in malaria cases in Vale do Acre. Most malaria cases in the micro-regions of Vale do Acre were reported in working age males indicating that people are predominantly exposed to malaria vector through their work and certain occupations pose greater risk. In contrast, in Vale do Juruá, it is speculated that transmission occurs near people's dwellings because of high incidence in people under 19 years of age. Although male cases are slightly more prevalent, high incidence of female cases further supports this assumption. Lower malaria incidence in people 60 years of age or more in both meso-regions is likely because naturally acquired immunity is built on lifetime exposure. Our findings of malaria incidence by age and sex suggest that work, housing, health conditions and access to public goods can greatly influence the intensity of transmission (Santos and Silva, 2011).

The spatial analysis identified clustering of deaths within the area of

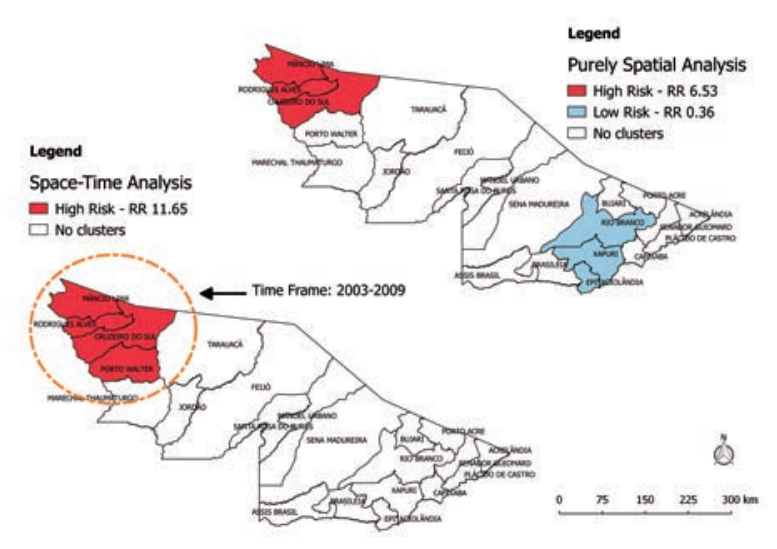

Figure 5. Locations of clusters of malaria deaths detected using purely spatial and spatio-temporal analysis.

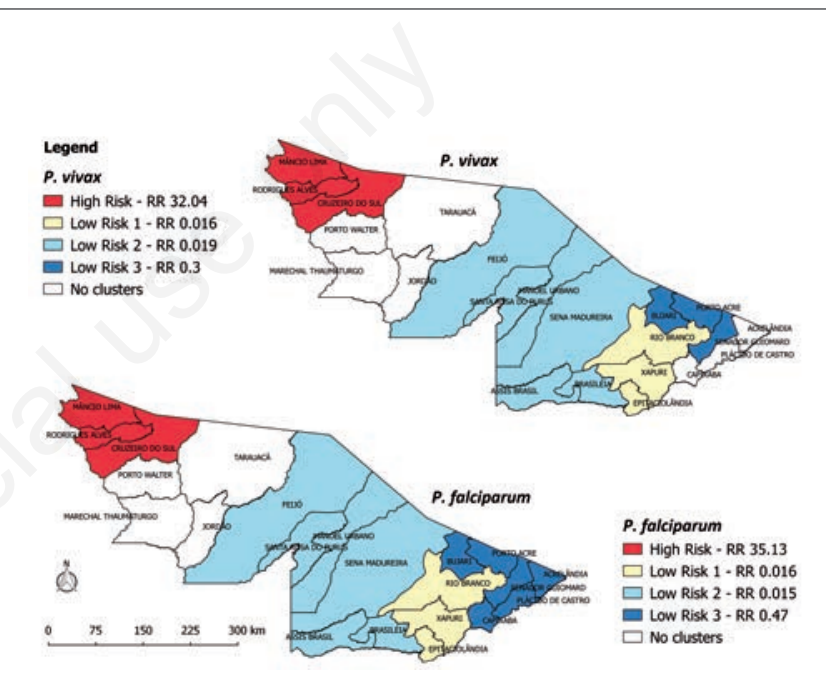

Figure 6. Locations of clusters of Plasmodium falciparum and Plasmodium vivax malaria cases detected using purely spatial analysis.

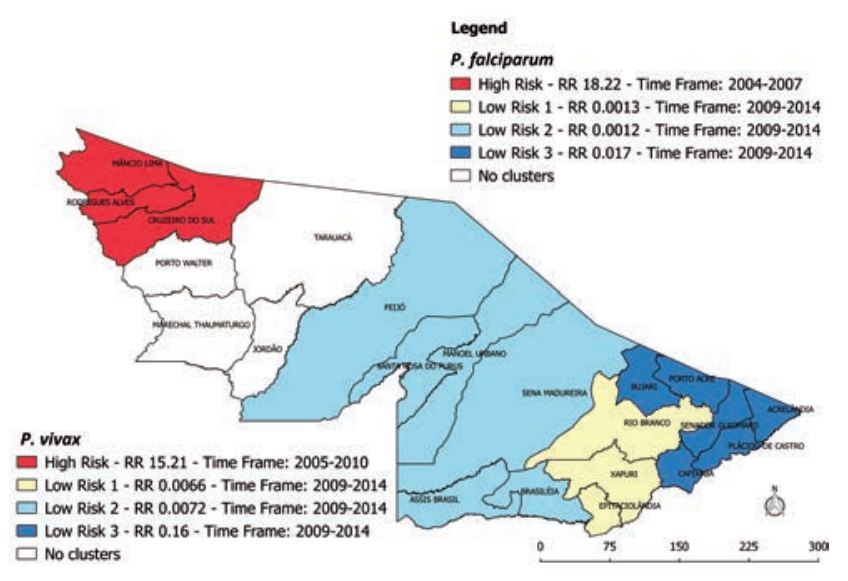

Figure 7. Locations of clusters of Plasmodium falciparum and Plasmodium vivax malaria cases detected using spatio-temporal analysis. 
Cruzeiro do Sul, Mâncio Lima, Rodrigues Alves, and Porto Walter from 2003 to 2009. Poor access to health services and inadequate local health care infrastructure were potentially associated with increased malaria mortality (Costa et al., 2010). While the epidemiological situation of malaria clearly aggravated from 2003 onwards with an increase in $P$. falciparum malaria cases, death rates gradually decreased in parallel with a worldwide trend. CFR was $0.02 \%$ during this same period. However, although $P$. vivax is less pathogenic than $P$. falciparum, it was the most prevalent malaria parasite in all micro-regions, similar to that reported in northern Brazil and nationwide. Tarauacá was the microregion with the highest (4.8) V/F ratio and consistently accounted for the lowest rate of malaria deaths in the study.

The recent reduction in malaria cases and deaths reflects the relative effectiveness of some actions: hiring and training of workers, expansion of laboratory networks, provision of equipment and supplies, community involvement in malaria care and prevention, and control actions including indoor residual spraying, insecticide-treated bed nets, and long-term environmental management of vector breeding sites. It is noteworthy that, in 2006 , the introduction of artesunatemefloquine combination as the first choice of treatment for $P$. falciparum malaria proved to be a successful strategy (Costa et al., 2010).

All these actions are consistent with the World Health Organization (WHO) guidelines for malaria control (WHO, 2015). WHO has underscored the need to strengthening local capacities for consistently assessing the progress of malaria control and implementing timely and appropriate interventions.

It should be mentioned that duplicity of records is an issue in malaria studies. This is because API is calculated from the number of positive parasite slides to indicate the annual risk of disease occurrence. Duplication occurs when the same patient undergoes more than one testing to ascertain cure, recrudescence or relapse. In addition, there is underreporting of deaths, especially those occurring in rural areas in children under 5 years. Another major limitation of the present study is the use of secondary databases. However, the analysis of secondary data can help to understand the epidemiological situation of a disease in space and time. Other limitations include the ecological design, underreporting of malaria cases, lack of consistent variable collection over the years analyzed, missing information of deaths by parasite species and lack of clear evidence for a causal relationship between fish farming and the proliferation of Anopheles mosquitoes in the State of Acre.

\section{Conclusions}

This study shows that combining secondary health data with spatial analysis techniques can help to understand the epidemiology of malaria. It was found that malaria is predominantly a focal disease with clusters of cases in the micro-region of Cruzeiro do Sul. Different spatial and spatio-temporal patterns of malaria morbidity and mortality by age, sex and parasite species were discovered. Since malaria incidence is influenced by factors related to regional characteristics, appropriate disease and vector control strategies must be implemented at each locality.

\section{References}

Abrams AM, Kleinman KP, 2007. A satscan macro accessory for cartog- raphy (smac) package implemented with sas software. Int J Health Geogr 6:6.

Atanaka-Santos M, Czeresnia D, Souza-Santos R, Oliveira RM, 2006. Epidemiological trends of malaria in the state of Mato Grosso, from 1980 to 2003. Rev Soc Bras Med Trop 39:187-92.

Braz RM, Duarte EC, Tauil PL, 2012. Epidemiology of malaria in the municipality of Cruzeiro do Sul, State of Acre, Brazil, in 2010: uses of a control chart at the local level. Rev Soc Bras Med Trop 45:5269.

Brazilian Ministry of Health, 2003. [Programa Nacional de Prevenção e Controle da Malária]. [Programme in Brazilian]. Brazilian Ministry of Health, Brasília, Brazil. Available from: bvsms.saude. gov.br/bvs/publicacoes/programa_nac_prev_malaria.pdf

Brazilian Ministry of Health, 2013. [Boletim epidemiológico: situação epidemiológica da malária no Brasil de 2000 a 2011]. [Bulletin in Brazilian]. Brazilian Ministry of Health, Brasília, Brazil.

Castro MCD, Singer BH, 2007. Environment and health: a methodological approach for spatial assessment of malaria transmission in colonization projects in the Brazilian Amazon. Rev Bras Estud Popul 24:247-62.

CDC, 2012. Laveran and the discovery of the malaria parasite. Available from: http:/www.cdc.gov/malaria/about/history/laveran.html

Ceccato P, Connor SJ, Jeanne I, Thomson MC, 2005. Application of geographical information systems and remote sensing technologies for assessing and monitoring malaria risk. Parassitologia 47:81-96.

Confalonieri UEC, 2005. [Saúde na amazônia: um modelo conceitual para a análise de paisagens e doenças]. [Article in Brazilian]. Estud Av 19:221-36.

Costa KM, De Almeida WA, Magalhaes IB, Montoya R, Moura MS, De Lacerda MV, 2010. Malaria in Cruzeiro do Sul (western brazilian amazon): analysis of the historical series from 1998 to 2008. Rev Panam Salud Publica 28:353-60.

Da Silva-Nunes M, Codeco CT, Malafronte RS, Da Silva NS, Juncansen C, Muniz PT, Ferreira MU, 2008. Malaria on the amazonian frontier: transmission dynamics, risk factors, spatial distribution, and prospects for control. Am J Trop Med Hyg 79:624-35.

DATASUS, 2015. Departamento de informática do SUS. Available from: http://www2.datasus.gov.br/

Delgado-Petrocelli L, Camardiel A, Aguilar VH, Martinez N, Cordova K, Ramos S, 2011. Geospatial tools for the identification of a malaria corridor in estado Sucre, a venezuelan north-eastern state. Geospat Health 5:169-76.

Franke J, Gebreslasie M, Bauwens I, Deleu J, Siegert F, 2015. Earth observation in support of malaria control and epidemiology: malareo monitoring approaches. Geospat Health 10:335.

IBGE, 2015. Available from: http://www.ibge.gov.br/estadosat/perfil.php? sigla $=\mathrm{ac}$

Kulldorf M, 2015. Satscan user guide for version 9.4. Available from: www.satscan.org/

Kulldorff M, Heffernan R, Hartman J, Assuncao R, Mostashari F, 2005. A space-time permutation scan statistic for disease outbreak detection. PLoS Med 2:e59.

Levinson W, 2014. Review of medical microbiology and immunology. McGraw-Hill, New York, NY, USA.

Machault V, Vignolles C, Borchi F, Vounatsou P, Pages F, Briolant S, Lacaux JP, Rogier C, 2011. The use of remotely sensed environmental data in the study of malaria. Geospat Health 5:151-68.

Mosha JF, Sturrock HJ, Greenwood B, Sutherland CJ, Gadalla NB, Atwal S, Hemelaar S, Brown JM, Drakeley C, Kibiki G, Bousema T, Chandramohan D, Gosling RD, 2014. Hot spot or not: a comparison of spatial statistical methods to predict prospective malaria infec- 
tions. Malaria J 13:53.

Natal D, Barata JMS, Lagos CBT, Rocha RM, 1992. Note on the culicidae (diptera: Culicidae) of the River Purus Basin, Acre, Amazonian, Brazil. Rev Saúde Pública 26:129-31.

Olson SH, Gangnon R, Silveira GA, Patz JA, 2010. Deforestation and malaria in Mancio Lima county, Brazil. Emerg Infect Dis 16:110815.

Santos IGD, Silva RDSUD, 2011. [Malária autóctone no município de
Rio Branco, Estado do Acre, Brasil, no período de 2003 a 2010]. [Article in Brazilian]. Rev Pan-Amaz Saude 2:31-7.

Valle D, Lima JM, 2014. Large-scale drivers of malaria and priority areas for prevention and control in the Brazilian Amazon region using a novel multi-pathogen geospatial model. Malaria J 13:443.

WHO, 2015. Ten facts on malária. Available from: http://www.who. int/features/factfiles/malaria/en/ 